\title{
A Sensitive Period for the Development of Motor Function in Rats: A Microgravity Study
}

\author{
Shannon M. Harding, ${ }^{1,2, *}$ Neeraj J. Singh ${ }^{3, *}$, and Kerry D. Walton ${ }^{2,4}$ \\ ${ }^{1}$ Department of Psychology, Fairfield University, Fairfield, CT; ${ }^{2}$ NASA Kennedy Space Center, Titusville, FL; 3 \\ Department of Neurology, Albany Medical Center, Albany, NY; ${ }^{4}$ Department of Neuroscience and Physiology, New \\ York University School of Medicine, New York, NY; ${ }^{*}$ These authors contributed equally to this manuscript.
}

\begin{abstract}
Spaceflight studies offer a unique opportunity to examine the impact of gravity on developing motor skills. Previously, we reported that young rats experiencing microgravity in low Earth orbit (LEO) beginning on postnatal day (P)14 showed impaired swimming, walking, and surface righting after returning to $1 \mathrm{~g}$, with immature motor skills persisting until adulthood. Here, we report on post-flight surface righting and swimming of rats experiencing spaceflight from P7 or P8. Litters with dams were flown aboard a space shuttle Space Transportation System (STS) 9-day (NIHR3, STS-72) or 16-day mission (Neurolab, STS90). Flight rats from both missions showed significantly fewer mature, age-appropriate righting tactics after landing compared to ground controls. Flight rats also had a steeper body angle while floating in the water before swimming,
\end{abstract}

Key words: Vestibular; Reflex; Critical Period;
Gravity
Correspondence to: Neeraj Singh, MD
Albany Medical Center Department of
Neurology
47 New Scotland Avenue, MC 70
Physicians Pavilion, 1st Floor
Albany, NY 12208
Phone: (518) 262-5226
Fax: (518) 262-6261
E-mail: sheeningraj@gmail.com

started swimming sooner, and swam faster. The effects on surface righting persisted for the duration of behavior tests (6 days [9-day mission] or 23 days [16-day mission]), after landing. Differences in pre-swimming behavior resolved by return day $(\mathrm{R}) 2$, and differences in swimming speed and posture resolved by R10. These data suggest that exposure to microgravity at a young age prevents the normal development of surface righting and that the normal development of swimming can recover if animals return from LEO by P16 or P24. These findings lend additional support to the existence of a critical period of development for motor function. However, studies are needed with improved housing during spaceflight to ensure that maternal offspring behavior is not disrupted, as was observed during the Neurolab mission.

\section{INTRODUCTION}

Early in development, the nervous system is influenced by experience, and sensory deprivation or augmentation can have long-lasting effects on the brain and behavior (Gabriel et al., 2012; Knudsen, 2004). When modifications to the environment produce long-term changes in the nervous system, a "sensitive" or "critical" period is said to exist, depending on the severity of the effects (Hubel and Wiesel, 1970; Wiesel, 1982). Sensitive and critical periods of development have 
been identified in several systems, including vision (Hubel and Wiesel, 1970; Wiesel and Hubel, 1963a; Wiesel and Hubel, 1963b), audition (Coleman et al., 1982; Harris and Rubel, 2006), olfaction (Frazier and Brunjes, 1988; Meisami, 1978), somatosensation (Baldi et al., 2000; Van der Loos and Woolsey, 1973), balance and orientation (Gabriel et al., 2012), and reproduction (Berenbaum and Beltz, 2011).

Although the existence of critical periods for motor skill development has been questioned, several studies have suggested that gravity is an important factor in this progression (Bagic et al., 2011; Brocard et al., 2003; Clarac et al., 1998; Hains et al., 2003; Walton, 1998; Walton et al., $2005 \mathrm{c}$ ). Clever, ground-based methods have been devised to remove or supplement gravitational forces and to examine their impact on developing motor skills. For example, hindlimb unloading studies (Morey-Holton et al., 2005) using rodents have identified two critical periods of development for motor skills: postnatal day (P)8 P13 for swimming and maintaining balance in the water, and P13-P31 for walking (Walton et al., 1992). In hypergravity studies, rats born and reared in an environment with twice the acceleration of normal Earth gravity $(2 \mathrm{~g})$ show impairments in motor coordination on a balance test (rotarod), which persist even one week after return to a normal Earth gravity environment (Abe et al., 2008). Rats conceived, born, and raised in hypergravity do not initially show the righting reflex, and show delays in righting their heads, although righting appears to be restored within three weeks (Bouet et al., 2003; Bouet et al., 2004; Wubbels et al., 2004). These findings support the existence of a sensitive period of development for the righting reflex.

Spaceflight offers a unique opportunity to investigate motor skill development in animals when gravity is removed as a stimulus, in contrast to hypergravity studies in which gravity is present but altered. Righting reflexes have been tested in offspring from pregnant rats that were flown in low Earth orbit (LEO) during development of the fetus' vestibular apparatus (Ronca and Alberts, 2000; Ronca et al., 2008). Differences in contact righting between flight and control pups did not reach significance; however, water immersion righting occurred less often in the flight animals on P1 and P3, but not on P5 (Ronca and Alberts,
2000; Ronca et al., 2008). In postnatal studies with young rats, we have reported that swimming and walking are faster after experiencing microgravity (Walton et al., 2005b; Walton et al., 2005c). Furthermore, neonatal rats flown in a 9day mission that launched when the animals were P15 demonstrated slower head turns during surface righting than control rats upon landing (Walton et al., 2005c). Surface righting skills typically progress during development from Uposture to corkscrew to axial (mature) tactics in rodents (Pellis et al., 1991) (see Figure 1). This progression to mature tactics was prevented in rats flown into space beginning on P14 (Walton et al., 2005c). Indeed, P14 rats flown aboard a 16-day mission (Neurolab, STS-90) showed immature tactics from landing until the last day of behavior testing 123 days later (Walton et al., 2005c). These findings suggest that a critical period of development exists where the elimination of gravitational input to the vestibular system can impede the normal development of this reflex.

Here, we report the findings for younger rats flown aboard two separate spaceflight missions. Young rats (P7 or $\mathrm{P} 8)$ experienced 9 or 16 days of spaceflight, and their surface righting and swimming were compared with those of animals that remained on Earth. We wished to determine: (1) if exposure to microgravity during this developmental period influenced the maturation of surface righting and swimming, (2) if these effects persisted after return to the $1-g$ environment of Earth, and (3) if surface righting and swimming after landing differed as a function of their age at launch. Based on previous findings (Walton, 1998; Walton et al., 2005b; Walton et al., 2005c), we hypothesized that surface righting and swimming would be abnormally immature in both flight groups, and that there would be a positive relationship between the time exposed to microgravity and the persistence of the immature surface righting and swimming skills.

\section{MATERIALS AND METHODS}

\section{Experimental Design}

Neonatal rats were launched into the microgravity environment of LEO on two separate space shuttle flights: a 9-day flight, the National Institutes of Health Rodent Experiment 3 (NIHR3, STS-72, Endeavour), and a 16-day flight, 
Neurolab (STS-90, Columbia). Rats were launched on P7 in the 9-day mission and on P8 in the 16-day mission (due to a 24 -h weather delay in the latter mission). The experimental designs

\section{A Axial Righting}

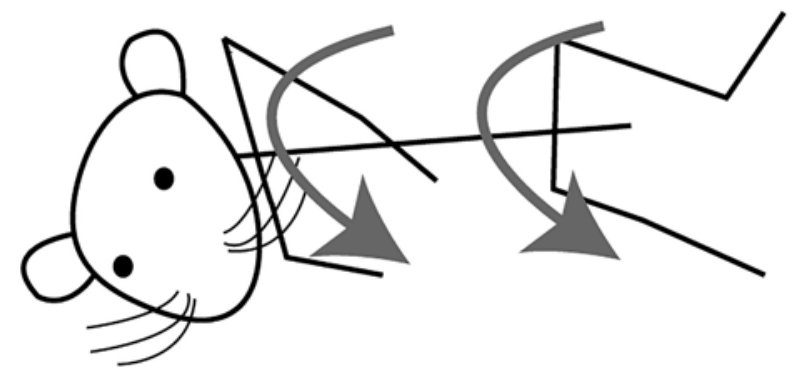

\section{B Corkscrew Righting}

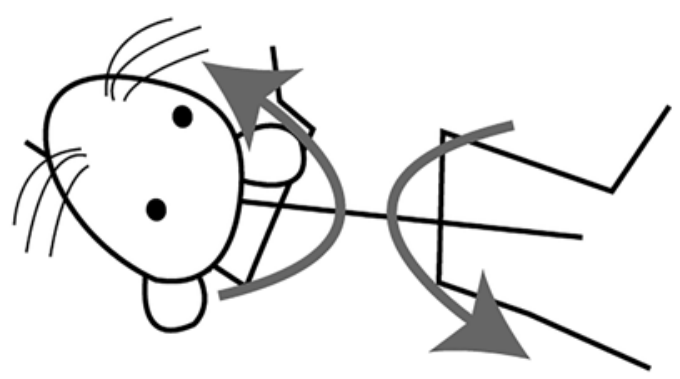

for both experiments compare motor skills in the neonatal rats flown in LEO with those in agematched control animals that remained on Earth during the space shuttle missions.
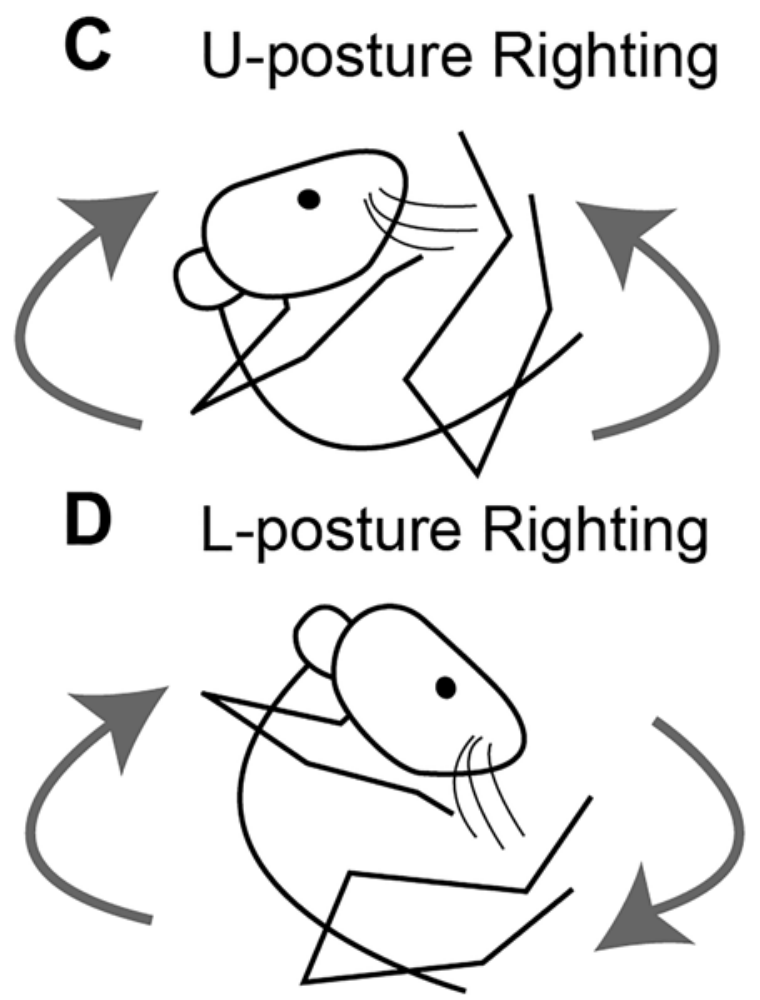

Figure 1. Surface righting tactics. The three major tactics are shown: (A) axial righting (seen in mature animals), (B) an intermediate stage tactic called corkscrew righting in which the head and forelimbs first rotate in one direction while the hindlimbs rotate in the opposite direction, and (C) a more immature tactic called $U$-posture righting in which the animal ventroflexes with quadrupedal extension before rotating its head and body in the same direction. (D) An extreme version of the U-posture righting is shown, in which the animals sat upright was termed $L$-posture righting.

\section{Animals}

Time-pregnant Sprague-Dawley dams were obtained from Taconic Farms (Germantown, NY), delivered to Kennedy Space Center (KSC), and individually housed in standard vivarium cages. These animals were placed on the same diet used in the spaceflight: food bars from Teklab Diet (American Institute of Baking). Each dam was verified to be pathogen free. A number of criteria were used to select litters, including water and food bar consumption of the dams, dam weight gain, maternal behavior, adequate weight gain of the pups, and optimal timing of birth in relation to the scheduled launch date. Dams that consumed at least $20 \mathrm{~g}$ over the first $24 \mathrm{~h}$ of transition to food bars and drank from a Lixit were eligible for selection. Dams were observed every $6 \mathrm{~h}$ to determine the birth window. Pups born within the birth window to the dams that had adequate weight gain were eligible for selection. Mixed litters of male and female pups were selected for the 9-day mission. The National Aeronautics and Space Administration (NASA) decided that only female animals would be included in the 16-day mission to eliminate the variable of sex.

\section{Groups and Housing}

Two groups of rats were formed for the 9-day mission: flight rats flown in space and housed in flight cages (FLT, $\mathrm{n}=10,4$ females and 6 males), 
and age-matched ground controls (AGC) housed in flight-like cages ( $\mathrm{n}=9,4$ females and 5 males). Four groups of female animals were formed for the 16-day mission: flight rats (FLT, $n=6$ ), agematched ground control animals housed in flightlike cages (AGC, $\mathrm{n}=8)$, age-matched ground control animals housed in standard vivarium cages (VIV, $\mathrm{n}=8$ ), and a group of younger animals (Basal, $\mathrm{n}=7$ ) that were tested on $\mathrm{P} 8$ to assess baseline skills. The basal animals were $\mathrm{P} 8$ because they were only included in the 16-day mission experimental design. Although age-matched ground control animals remained at the $\mathrm{KSC}$, the terms "launch" and "landing" are applied to all groups. Animals were P7 or P8 on the day of launch and P16 or P24 on the day of landing. The 16-day mission launched after a 24-h delay during which the animals remained in the orbiter (FLT group) or life science support facility (all ground controls).

Local government authorities, the NASA and the New York University Institutional Animal Care and Use Committee (IACUC) approved all experimental procedures. The animals were cared for and sacrificed according to NIH, NASA, and New York University School of Medicine guidelines. Animals in the Neurolab mission were used for anatomical studies after humane sacrifice (DeFelipe et al., 2002; Raymond et al., 2000).

\section{Surface Righting Experiments}

For each trial, an animal was placed supine on a large ( $2.5^{\prime}$ by $2.5^{\prime}$ ) foam pad. The head was held straight or tilted approximately 90 degrees about the roll axis. When an animal was immobile and relaxed, it was quickly released. This procedure was repeated up to 20 times for each head position. A single high-speed camera recorded the animal's movements (NAC, 200 or $500 \mathrm{fps}$ ). After the 9-day mission, surface righting was tested daily in the KSC life science support facility from the day of landing (return day [R]0) until 6 days later (R0-R6). After the 16-day mission (Neurolab), surface righting was tested 2, 3, 5, 7, 10 , and 23 days after landing at KSC.

The posture of the animal during surface righting and the time required to complete the movement were evaluated. Posture during each turn was assigned to one of three categories (Pellis et al., 1991; Walton et al., 2005c): (1) axial righting (Figure 1A), (2) corkscrew (Figure 1B), and (3) U-posture (Figure 1C). During our analysis, we also observed an extreme form of ventroflexion, where the animals sat upright. This was designated as an "L" posture (Figure 1D), as previously reported (Walton et al., 2005b). For each animal, the occurrence of each posture was expressed as a percentage of the total number of trials for that day. These categorical data are expressed as the group mean of the individual animal means.

Three values for surface righting times were determined using frame-by-frame analysis: when the animal was free to move (Start), when the head rotated 90 degrees (Head), and when both hindlimbs touched the ground to complete the movement (Hindlimbs). Using these data, the times to turn the head (Head-Start) and the hindquarters (Hindlimbs-Head), and to complete righting (Hindlimbs-Start) were calculated. Only trials in which the entire turn could be seen clearly (between 12 and 15 trials per animal per day) were included in the data analysis.

\section{Swimming Experiments}

Swimming measurements and analysis followed the same protocol as the older animals on the 9-day and 16-day missions (Walton et al., $2005 b$ ). Since they were participating in other experiments, not all of the animals were available for the swimming test every day. Individual animals were videotaped while swimming on R0R5, R7 (controls), R8 (flight), R9, and R14 after 9 days in LEO or on R1-R3, R7, R10, R16, R20, and R23 after 16 days in LEO. For each swimming trial, an animal was placed carefully at one end of a swimming lane $\left(30^{\prime \prime} \times 12^{\prime \prime}\right)$ in a tank maintained at $32-35^{\circ} \mathrm{C}$. A platform at the other end of the lane allowed the animals to leave the water. Animals were able to complete between 8 and 12 trials during the 2-min period allotted for swimming on each test day. Swimming was videotaped at 60 frames per second (fps). After swimming, the animals were towel-dried and returned to their cages, where they groomed, ate normally, and were quickly accepted by the other animals.

Trials were selected for analysis in which animals could be seen clearly and were not touching the side of the tank. After the 16-day mission (but not the 9-day mission), frame-byframe analysis was used to evaluate behavior of 
the animals when they were first placed in the water. Three parameters were measured: (1) posture before beginning to swim, (2) movements used to initiate swimming, and (3) interval between placement in the water and the first swimming stroke. Frame-by-frame analysis was also used to measure swimming stroke duration in the animals from both missions. Each stroke was divided into two phases: (1) power phase, those frames during which the hindlimb moved backward, and (2) return phase, those frames during which the hindlimb moved forward. A sum of the power phase frames and return phase frames gave the number of frames in each stroke. The temporal resolution was limited by the duration of one frame (16.67 $\mathrm{ms}$ at $60 \mathrm{fps})$.

\section{Statistical Analysis}

Surface righting, swimming, and preswimming behavior were compared between flight and control animals using the grand means for each animal group. Statistical analysis was carried out in the SPSS environment (SPSS Statistics, IBM) using the independent sample ttest (for one independent variable) or one-way analysis of variance (ANOVA) with the least significant difference (LSD) method for post hoc analysis (for more than one independent variable). A level of $\mathrm{p}<0.05$ was considered to be statistically significant. The litter that each animal came from was not known in every case. Thus, as in our other publications (Walton et al., 2005a-c), we considered that independent observations could be made on these animals, independent of their litter. Values in the text are mean \pm s.e.m. Three levels of significance are marked in the figures: ${ }^{*} \mathrm{p}<0.05, * * \mathrm{p}<0.01$, and $* * * \mathrm{p}<0.001$.

\section{RESULTS}

The data from both the 9-day and the 16-day mission are presented together. Differences between the animals flown in space and those that remained on the ground were apparent in both surface righting and in swimming immediately after landing. Four aspects of surface righting are considered: righting tactics used soon after landing (Figures $2 \& 3$ ), change in tactics after return to $1 \mathrm{~g}$ (Figure 4), the effect of head position on righting tactic (Table 1), and the speed of righting (Table 2). Three aspects of swimming are

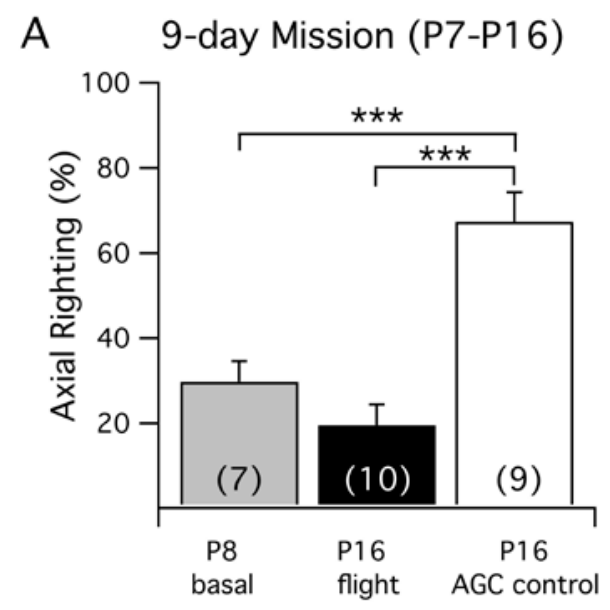

B 16-day Mission (P8-P24)

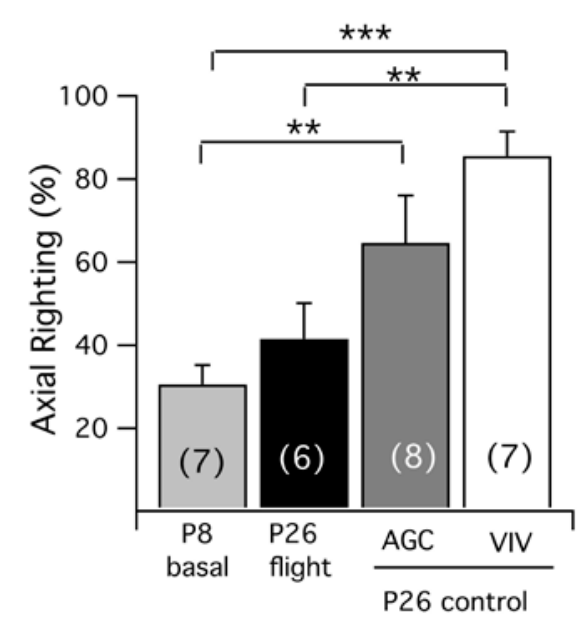

Figure 2. Axial righting on the day of launch and on the first test day after spaceflight in both missions. (A) On the day of landing after the 9-day mission, the control animals (AGC, open bars) used axial righting significantly more often than flight animals (flight, black bars) or animals on the day of launch (basal, gray bars). (B) On the first test day (R2) after the 16-day mission, both groups of control animals (AGC, dark gray bars; VIV, open bars) used axial righting significantly more often than the animals on the day of launch (basal, light gray bars). The VIV animals also used axial righting significantly more often than the flight animals, but there were no differences between the AGC animals and either the flight or the VIV group. Data are the grand means of the mean for each animal for use of axial righting expressed as the percentage of all tactics used, presented as mean \pm SEM. * $\mathbf{p}<0.05$, ** $\mathbf{p}<0.01, * * * \mathbf{p}<0.001$, one-way ANOVA. Basal values were measured only for the 16-day mission, and are presented in both panels for comparison. (The number of animals tested is given in each column.) 
considered: pre-swimming behavior (Figure 5), swimming style (as measured by posture while swimming, and joint angle ranges of motion) (Table 4), and swimming rate (expressed as stroke duration) (Figure 6). We also measured the weights and rates of weight gain for each group of animals after landing to account for any effects of nutrition on our findings (Figures $7 \& 8$ ).

\section{Surface Righting}

The use of axial surface righting differed between flight and control animals on the first day of testing after landing (Figure 2). In the 9-day mission (Figure 2A), on the day of landing, there was a significant difference between groups in the frequency of axial (mature) righting as determined by one-way ANOVA $(\mathrm{F}(2,23)=20.28, \mathrm{p}=0.0001)$. Post-hoc tests revealed that the AGC control group used axial righting more often than launchage (basal) animals $(\mathrm{p}=0.0001)$ or flight animals $(p=0.0001)$. There was no difference between the basal and the flight animals.

After the 16-day mission, on R2, there was a significant difference between groups in the frequency of axial righting $(\mathrm{F}(3,24)=8.455$, $\mathrm{p}=0.001$ ) (Figure 2B). Post-hoc tests revealed that the control groups (AGC and VIV) used axial righting significantly more often on the first day of testing compared to basal animals $(p=0.007$ and $\mathrm{p}=0.0001$, respectively). The control groups also used axial righting more frequently than flight animals, and this reached significance with respect to the vivarium group $(p=0.002)$. There was no difference between the basal and the flight animals, as in the 9-day mission.

Next, the frequency of axial righting was compared in flight and control animals as a function of time after landing (Figure 3). After returning to $1 \mathrm{~g}$, the flight animals from the 9-day mission increased their use of axial righting from R0 to R5 (Figure 3A $\square$ Differences between the two groups of animals were significant on R0-R6. Flight animals reached control levels on R7. Significant differences were found between flight and control animals from the day of landing through day 6 (see Supplementary Table 1 for $t$ values).

A different pattern was seen after the 16-day mission (Figure 3B). The flight animals did not show an increase in use of axial righting over the 23-day testing period after landing. There was no statistically significant difference between days by the flight animals (Figure 3B, $\bullet$ ). There was a statistically significant difference between groups as determined by one-way ANOVA on all test days except on R10 (when a fewer number of animals were available for testing). A post-hoc test revealed a significant difference between flight and AGC control animals on all test days except on R2 and between flight and VIV control animals on all days (see Supplementary Table 2 for statistics). The proportion of axial righting used by control animals did not change over most of the testing period for either mission (Figure 3).

To visualize the immature righting tactics the animals used after landing, the mean occurrence of each righting tactic, expressed as a percentage, was plotted for both missions as a function of age for control animals (Figure 4A \& B) and as a function of days after landing for the flight group (Figure 4C \& D). In control animals from both missions, axial righting was the predominant tactic and the use of corkscrew righting and righting involving ventroflexion remained stable post-flight (Figure 4A \& B).

After the 9-day mission, corkscrew righting was the predominant immature tactic used by the flight animals (Figure 4C, gray). Compared to flight animals, corkscrew righting was used significantly less often by control animals on R1, $\mathrm{R} 2$, and R5, and righting with ventroflexion was used less often by control animals on R0, R2, and R5 (Supplementary Table 1).

After the 16-day mission, righting with ventroflexion was the predominant immature tactic used by the flight animals (Figure 4D, black). There was a statistically significant difference for this set of immature tactics on each test day between flight and the AGC and the VIV control groups, as determined by one-way ANOVA (Supplementary Table 2). In contrast to the findings for the 9-day mission, there was no significant difference in the use of corkscrew righting between the flight and either of the control groups.

The increased use of ventroflexion by the flight animals after the 16-day mission (Figure 4) prompted us to ask if head position at the beginning of the righting reflex influenced the tactic used, as we had observed in older rats from this mission (Walton et al., 2005c). In these 
A

9-day Mission (P7-P16)

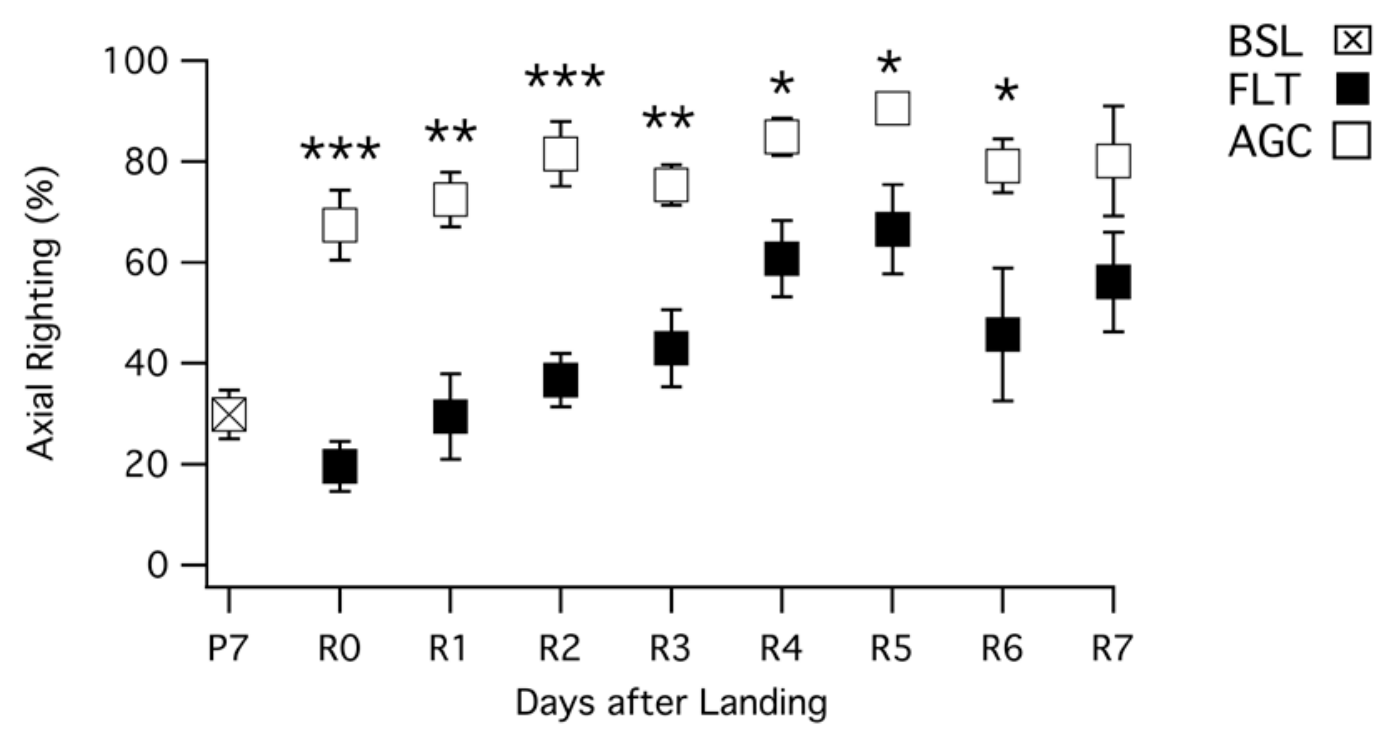

B

16-day Mission (P8-P24)

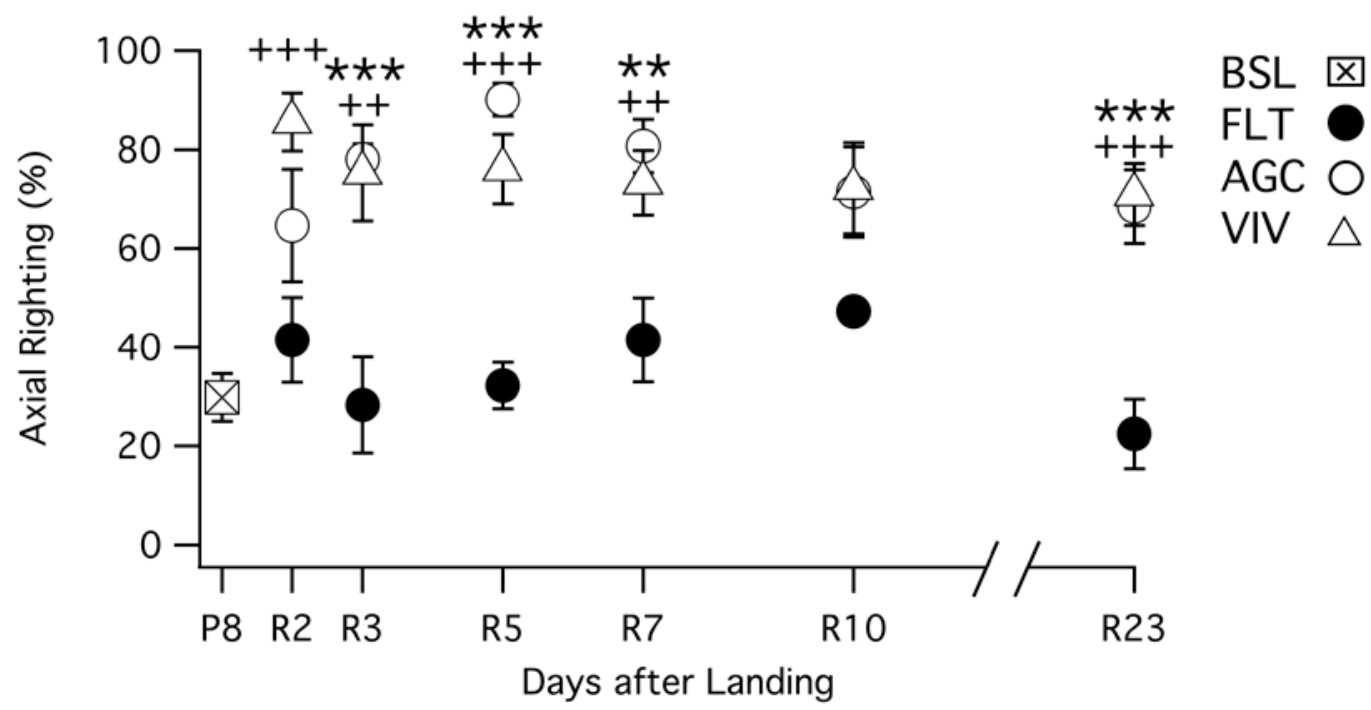

Figure 3. Use of axial righting over the test period after return from spaceflight. (A) After the 9-day mission, the flight animals used axial righting significantly less often than the control animals between $\mathrm{RO}$ and $\mathrm{R6}$ (AGC, R0-3, n=9; R4-6, n=8; R7, n=3, FLT, R0, n=10; R1-6, n=9; R7, n=8). (B) After the 16-day mission, the flight animals used axial righting significantly less often than either group of control animals throughout the testing period, except on R2 for the AGC group, and on R10 for both control groups (AGC, R2-7, 23, n=7; R10, $n=4$ : FLT, R2-23, $n=5$ : VIV, R2-7, $n=6 ; R 3, R 4, R 23, n=7 ; R 10, n=4)$. Data are the grand means of the mean for each animal on each day for use of axial righting expressed as the percentage of all tactics used, presented as mean \pm SEM. * and $+\mathbf{p}<0.05$, ** and $++\mathbf{p}<0.01$, *** and +++ p $<0.001$, ANOVA. (See Supplementary Tables 1 and 2 for ANOVA and t-test values.) 
Righting Tactics After Return from Space Flight

A

A 9-day Mission (P7-P16)

Ground Controls

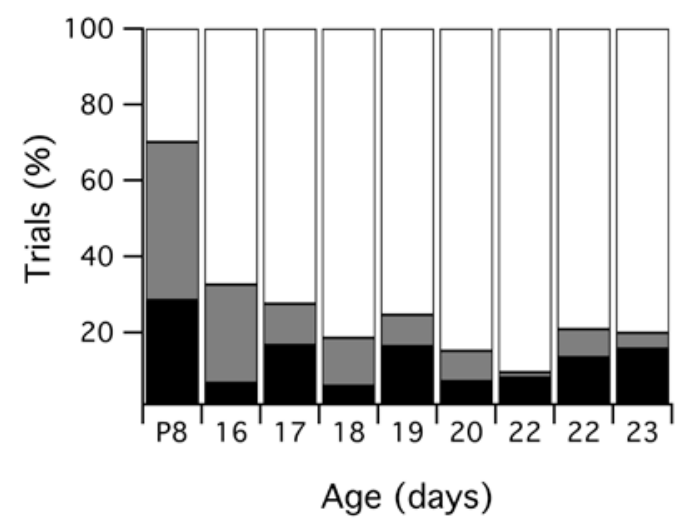

C

Flown in Space

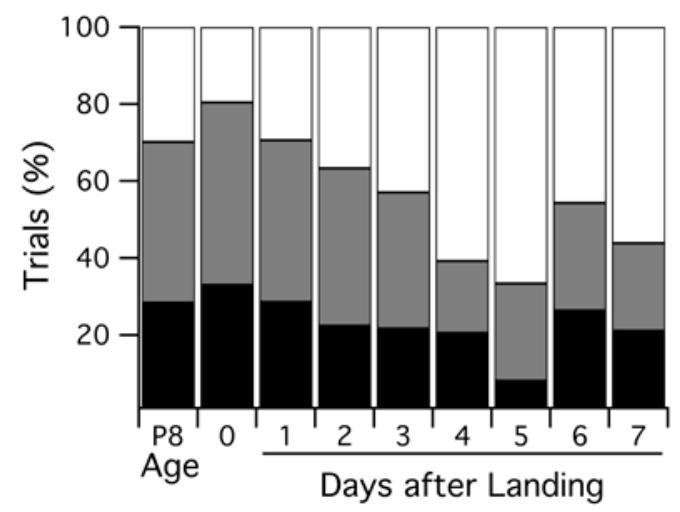

B

16-day Mission (P8-P24)

Ground Controls

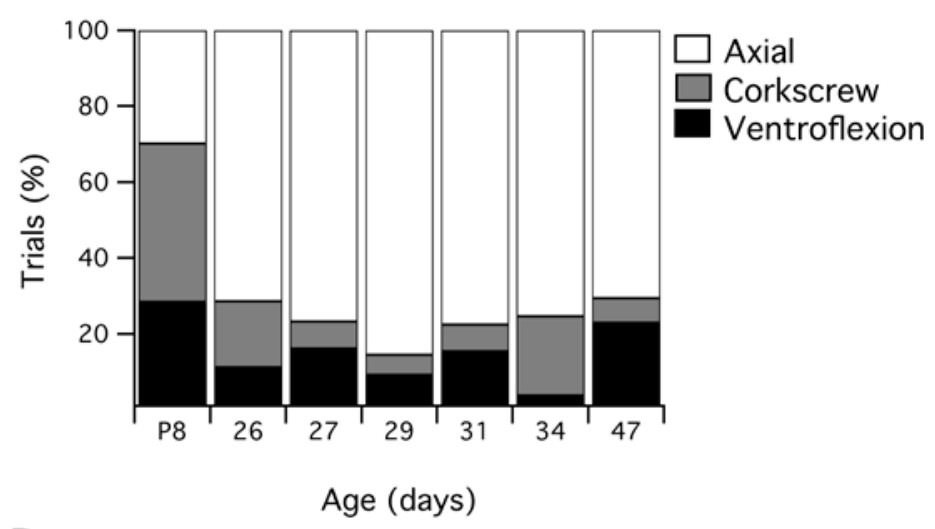

Flown in Space

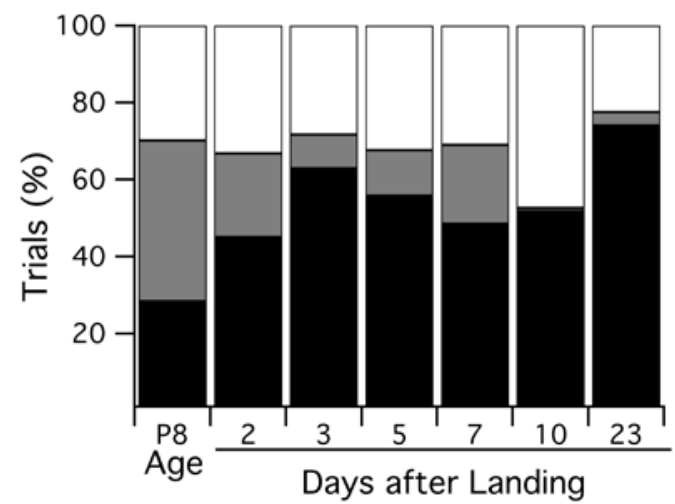

Figure 4. Surface righting tactics after return from the 9-day (A \& C) or 16-day mission (B \& D). The data for basal animals were collected only for the 16-day mission, but are presented in all panels for comparison. Axial righting predominated in control animals after landing for both the 9-day (A \& B) and 16-day missions. (C) The distribution of righting tactics in flight animals on the day of landing after the 9-day mission was indistinguishable from that of the basal animals. Corkscrew righting predominated in flight animals after the 9-day mission; they used this tactic significantly more often than control animals on R0, R2, and R4. Flight animals also used tactics involving ventroflexion significantly more often than control animals on days R0, R2, and R4. (See Supplementary Table 1.) (D) Righting tactics using ventroflexion predominated in flight animals after the 16-day mission throughout the testing period. Data for P8 (the day before flight for the 16day mission) are included. Since there were no significant differences between the AGC the VIV control groups in the righting tactics used after the 16-day mission, they were combined into one control group in Figure 4C \& D. Data are the grand means of the mean for each animal for each tactic expressed as the percentage of trials in which each tactic was used on each day. (See Supplementary Tables 1 and 2 for ANOVA and t-test values. The number of animals is the same as in Figure 3.)

experiments, the animals were released from the supine position with the head held straight or rotated 90 degrees about the roll axis. Ground control animals used axial, corkscrew, or U- posture righting on $\mathrm{R} 2$ when they were released from the head straight position (Table 1). When they were released from the head rotation position, they used axial or corkscrew righting, 
but not U-posture righting (Table 1). Head position did not have a significant effect on which tactic was used by the control animals; however, tilting the head did lead to a reduction in the use of "U" and "L" positions across groups (Table 1). In contrast, the initial head position had a significant effect on righting tactics in the flight animals (Table 1). Indeed, head rotation significantly increased the use of axial righting, decreased the use of U-posture righting, and eliminated the use of L-posture and $\mathrm{U}$ and $\mathrm{C}$ righting.
To determine whether the speed of surface righting was influenced by microgravity, righting times were compared for the various tactics used at launch (P8) and on R2 (P26) after the 16-day mission (Table 2). Data from the 9-day mission have been reported previously (Walton, 1998). The study found that both control and flight animals were significantly faster than basal animals for all of these tactics $(\mathrm{p}<0.001)$. Differences between flight and control animals did not reach significance, but it is interesting to note that flight animals were faster than the controls.

Table 1. Effect of initial head position on righting strategy after a 16-day spaceflight. Data are the grand mean \pm standard error of the mean for each animal for each tactic expressed as the percentage of all tactics used after release from each head position.

\begin{tabular}{llllllll}
\hline \multicolumn{1}{c}{ Group } & $\begin{array}{c}\text { Head } \\
\text { position }\end{array}$ & Axial (\%) & $\begin{array}{c}\text { Corkscrew } \\
(\%)\end{array}$ & $\begin{array}{c}\text { U-posture } \\
(\%)\end{array}$ & $\begin{array}{c}\text { U and C } \\
(\%)\end{array}$ & $\begin{array}{c}\text { L-posture } \\
(\%)\end{array}$ & $\begin{array}{c}\text { Total } \\
(\%)\end{array}$ \\
\hline $\begin{array}{l}\text { Control } \\
(\mathbf{n}=\mathbf{9})\end{array}$ & Straight & $75.4 \pm 9.5$ & $5.6 \pm 3.9$ & $16.8 \pm 8.5$ & 0 & 0 & 100 \\
Flight & Rotated & $91.3 \pm 4.5$ & $8.7 \pm 4.5$ & 0 & 0 & 0 & 100 \\
$(\mathbf{n}=\mathbf{6})$ & Straight & $14.5 \pm 6.6^{1}$ & $7.5 \pm 4.8$ & $35.3 \pm 8.0^{2}$ & $11.4 \pm 5.9$ & $31.31 \pm 15.3$ & 100 \\
& Rotated & $85.6 \pm 10.9$ & $11.1 \pm 11.1$ & $3.3 \pm 3.3$ & 0 & 0 & 100 \\
\hline${ }^{1}=-5.569, \mathrm{df}=10, \mathrm{p}<0.0001 ;{ }^{2} \mathrm{t}=3.671, \mathrm{df}=10, \mathrm{p}<0.004$ & & & &
\end{tabular}

Table 2. Time required for righting in basal, control, and flight animals after a 16-day spaceflight. Data are the grand means \pm standard error of the mean for each animal for each tactic.

\begin{tabular}{|c|c|c|c|c|}
\hline Posture & Group & Mean (ms) & Standard error of the mean (ms) & $\mathrm{n}$ \\
\hline \multirow[t]{3}{*}{ Axial } & Basal & 972 & 68 & 7 \\
\hline & Control & 163 & 4 & 16 \\
\hline & Flight & 192 & 13 & 6 \\
\hline \multirow[t]{3}{*}{ Corkscrew } & Basal & 1323 & 74 & 7 \\
\hline & Control & 202 & 10 & 10 \\
\hline & Flight & 237 & 27 & 4 \\
\hline \multirow[t]{3}{*}{ L-posture } & Basal & - & - & 0 \\
\hline & Control & 665 & 14 & 4 \\
\hline & Flight & 422 & 38 & 2 \\
\hline \multirow[t]{3}{*}{ U-posture } & Basal & 899 & 51 & 6 \\
\hline & Control & 250 & 14 & 6 \\
\hline & Flight & 258 & 20 & 4 \\
\hline \multirow[t]{3}{*}{$\mathrm{U}$ and $\mathrm{C}$} & Basal & 1213 & 95 & 6 \\
\hline & Control & 240 & 8 & 3 \\
\hline & Flight & 349 & 78 & 4 \\
\hline
\end{tabular}




\section{Swimming}

Pre-swimming behavior was studied after the 16-day mission. When the flight and control animals were first placed in the water, they started to swim, floated before beginning to swim, or tried to get out of the water by climbing up the tank (Figure 5). There were no significant differences among the three groups of animals with respect to the frequencies of any of these behaviors, although flight animals floated less often than either group of controls until R10.

While floating, the flight animals twisted about their cephalocaudal axis. To understand this better, we measured the angle between the plane of the animal's back and the horizontal surface of the water. On R1, the "body angle" while floating was greater in the flight $\left(30.50 \pm 5.8^{\circ}\right)$ than in the AGC $\left(7.86 \pm 1.844^{\circ}\right)$ or VIV $\left(10.83 \pm 3.0^{\circ}\right)$ control animals as determined by one-way ANOVA ( $\mathrm{F}(2$, $15)=11.399, p=0.001)$. A post-hoc test revealed significant differences between flight and AGC $(p=0.0001)$ and between flight and VIV $(p=0.002)$ animals. From R2 onwards, the flight animals sank less in the water while floating, and their body angles while floating were not significantly different than those of the control animals.

We next measured how long the animals floated before they began to swim. On the first day they were put in the water (R1, P24), the flight animals floated for a significantly shorter period of time $(2.24 \pm 0.25 \mathrm{~s})$ than the control animals before starting to swim (AGC $(4.86 \pm 1.14$ $\mathrm{s})$; VIV $(4.32 \pm 0.38 \mathrm{~s})$ as determined by one-way ANOVA $(F(2,17)=7.390, p=0.004)$. Post-hoc tests revealed a difference between flight and AGC ( $p=0.004)$ and between flight and VIV $(p=0.002)$ animals. However, after R1, there were no significant differences among the three groups of animals.

Stroke duration (measured as the time needed to complete one hindlimb stroke) was used as an estimate of swimming speed after the 9-day (Figure 6A) and 16-day mission (Figure 6B). Over the testing period, the swimming rate of the control animals from either mission did not change significantly. Following the 9-day mission, three flight animals tried to leave the water on R0 and did not swim until R1. Differences between flight and control animals were seen only on day 5 (Figure 6A). On that day, control animals swam faster than flight animals $(\mathrm{t}(15)=2.898, \mathrm{p}<0.05)$.

After the 16-day mission (Figure 6B), there was a statistically significant difference in stroke duration among the groups as determined by oneway ANOVA on R2 $(\mathrm{F}(2,18)=20.308, \mathrm{p}=0.0001)$, R3 $\quad(\mathrm{F}(2,17)=11.638, \quad \mathrm{p}=0.001), \quad \mathrm{R} 7$ $(\mathrm{F}(2,16)=5.367, \quad \mathrm{p}=0.016) \quad$ and $\mathrm{R} 16 \quad(\mathrm{~F}(2$, $17)=6819, \mathrm{p}=0.007)$. The post-hoc test revealed an effect of spaceflight as well as a cage effect for this parameter. Indeed, on R2 flight animals swam faster (shorter stroke duration) than both VIV $(p=0.0001)$ and AGC $(p=0.0001)$ control animals. On R3, R7, and R16, flight animals swam faster than the vivarium controls $(\mathrm{p}=0.0001, \mathrm{p}=0.005$, and $\mathrm{p}=0.004$, respectively). The AGC controls swam faster than the VIV controls on R3 $(\mathrm{p}=0.003)$ and $\mathrm{R} 16(\mathrm{p}=0.010)$, indicating a cage effect. There was no significant difference among the groups after R16.

In order to compare swimming in the animals from both NASA missions, stroke duration was plotted as a function of age in days after landing (Figure 6C). Swimming speed increased from that measured before launch (basal, P8) in flight as well as in control animals. Note that the flight animals from the 16-day mission swam faster (shorter stroke duration) than those from the 9-day mission even though they were close in age (near P25 and P30).

Ankle and knee joint angles were measured for the flight and control animals on the day of landing (R0) and on R1, R7, and R14 following the 9-day mission (Table 3). While swimming, the flight animals tended to move their foot over a wider arc than controls (greater ankle angle range), but this difference was only significant on R7. There were no differences in the knee angle between the two groups.

\section{Differences in Weight between Flight and Control Animals}

Differences in the body weight between flight and control animals were seen after the 9-day mission. Because both female and male animals were included in the mission, their weights are plotted separately (Figure 7). On the day of landing, both female and male flight animals were lighter than their control counterparts (female, $\mathrm{t}(7)=3.911, \mathrm{p}=0.028$; male, $\mathrm{t}(8)=5.379, \mathrm{p}=0.001$ ). There was no difference in the rate of weight gain 
over the first month after landing between flight and control animals (Figure 7B). The weight of the animals over three time periods is shown for female (Figure 7C) and male (Figure 7D) animals. The only significant difference in weight between flight and control animals was seen in the females for the 11-15-day post-flight period $(\mathrm{t}(6)=2.51$, $\mathrm{p}<0.046$ ).

Due to the difference in weights between female and males after the 9-day mission, NASA decided to include only female animals in the 16- day mission. An analysis of their body weights showed significant differences among the three animal groups on the day of landing (R0) (Figure $8 \mathrm{~A})$. There was a statistically significant difference between groups as determined by oneway $\operatorname{ANOVA}(\mathrm{F}(2,19)=66.892, \mathrm{p}=0.0001)$. A post-hoc analysis revealed that flight rats were lighter than controls in flight-like cages (AGC) $(\mathrm{p}=0.0001)$ and in vivarium cages (VIV) $(\mathrm{p}=0.0001)$. There was also a cage effect. Controls

Righting Tactics After Return from Space Flight

A 9-day Mission (P7-P16)

Ground Controls

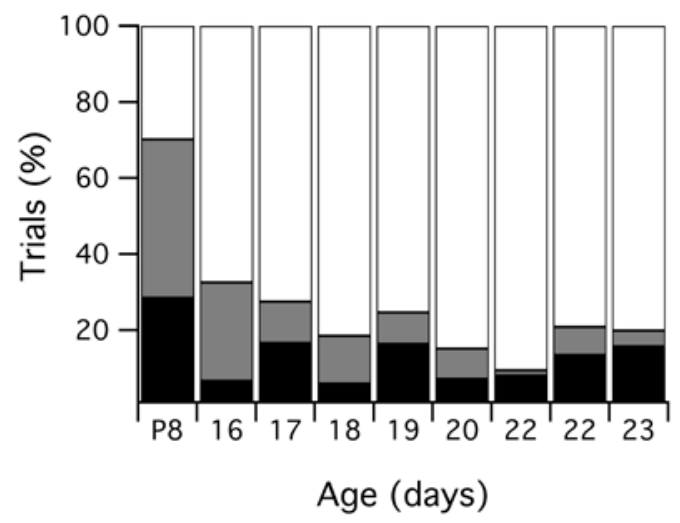

C

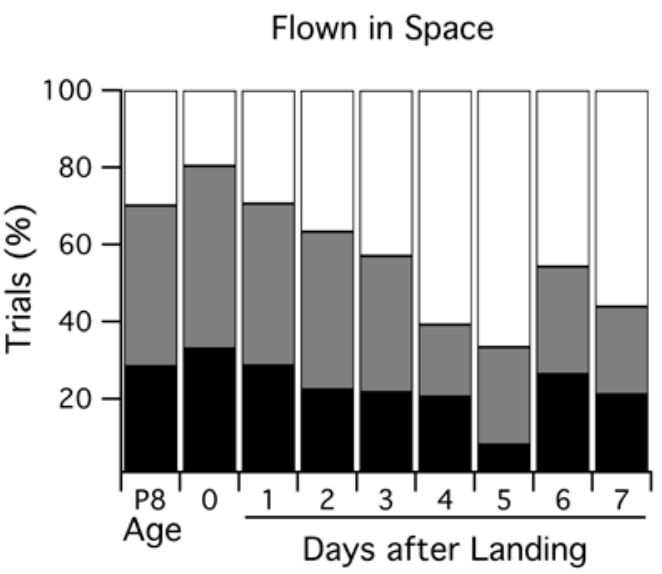

B

16-day Mission (P8-P24)

Ground Controls

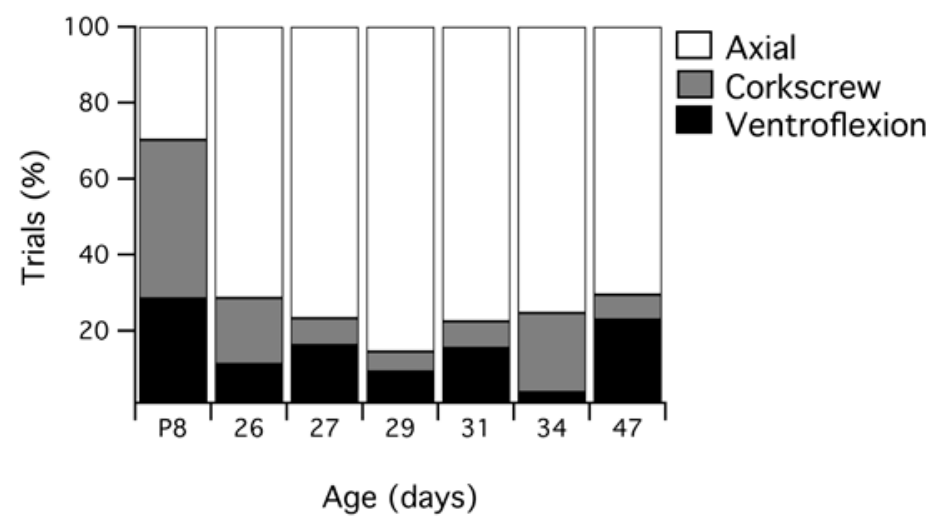

Flown in Space

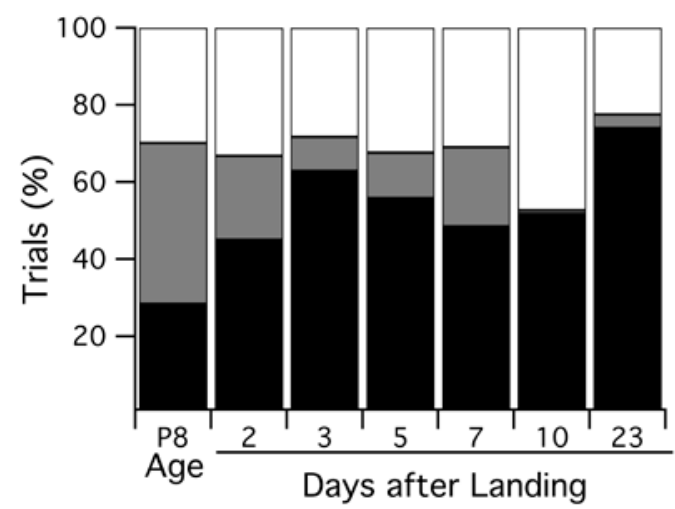

Figure 5. Distribution of behaviors of flight and control animals when they were first placed in the water after the 16-day mission (expressed as a percentage of trials). (A) On the first day of testing, the animal in all three groups favored trying to leave the water, but the flight animals floated less often than the controls. (B) On R2, all the animals swam when they were placed in the water, but the flight animals still floated less often than the controls. (C) Behaviors were similar in all the groups on R3, R10, and R20. Therefore, the data were pooled. Data are the grand means $\pm \mathrm{SE}$ of the mean for each animal for each behavior expressed as the percentage of trials in which each behavior was used on each day. 
A

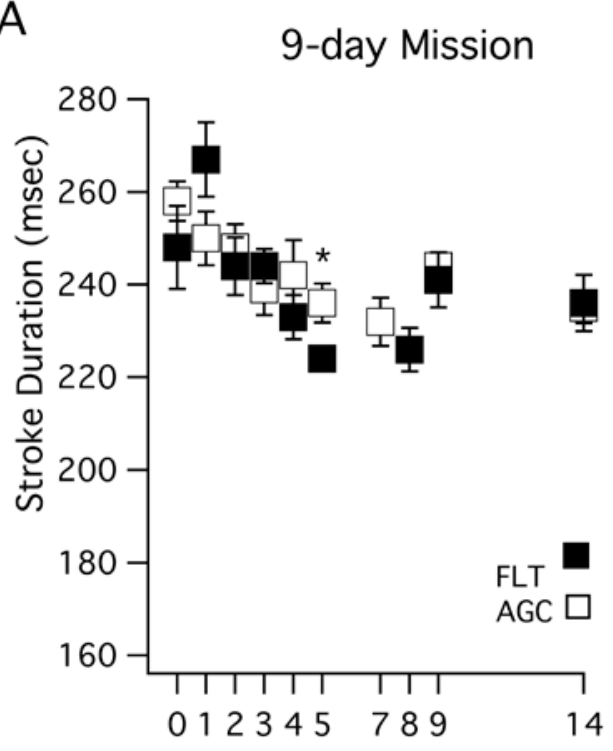

Days after Landing
B

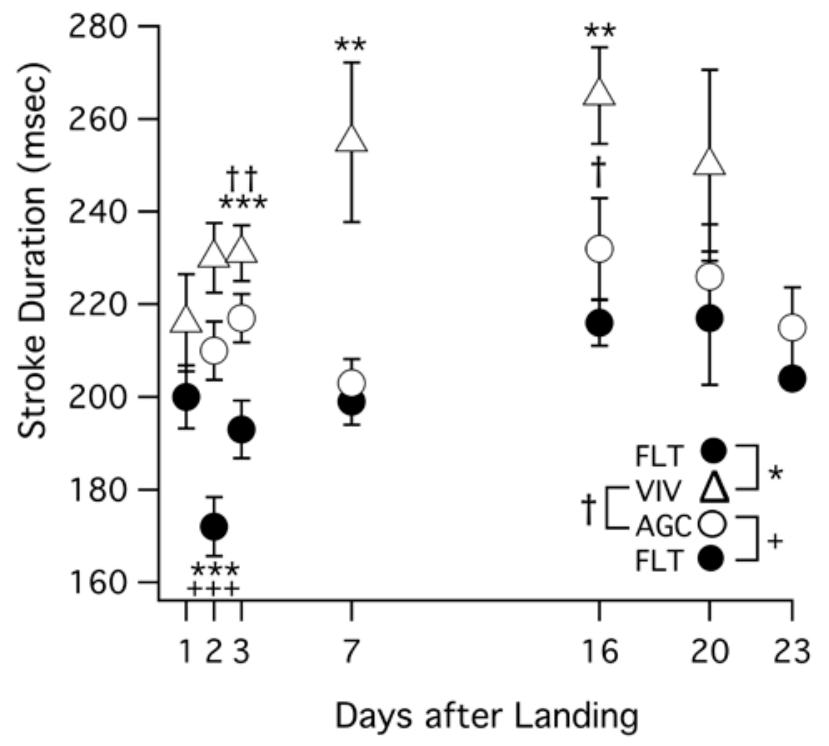

C

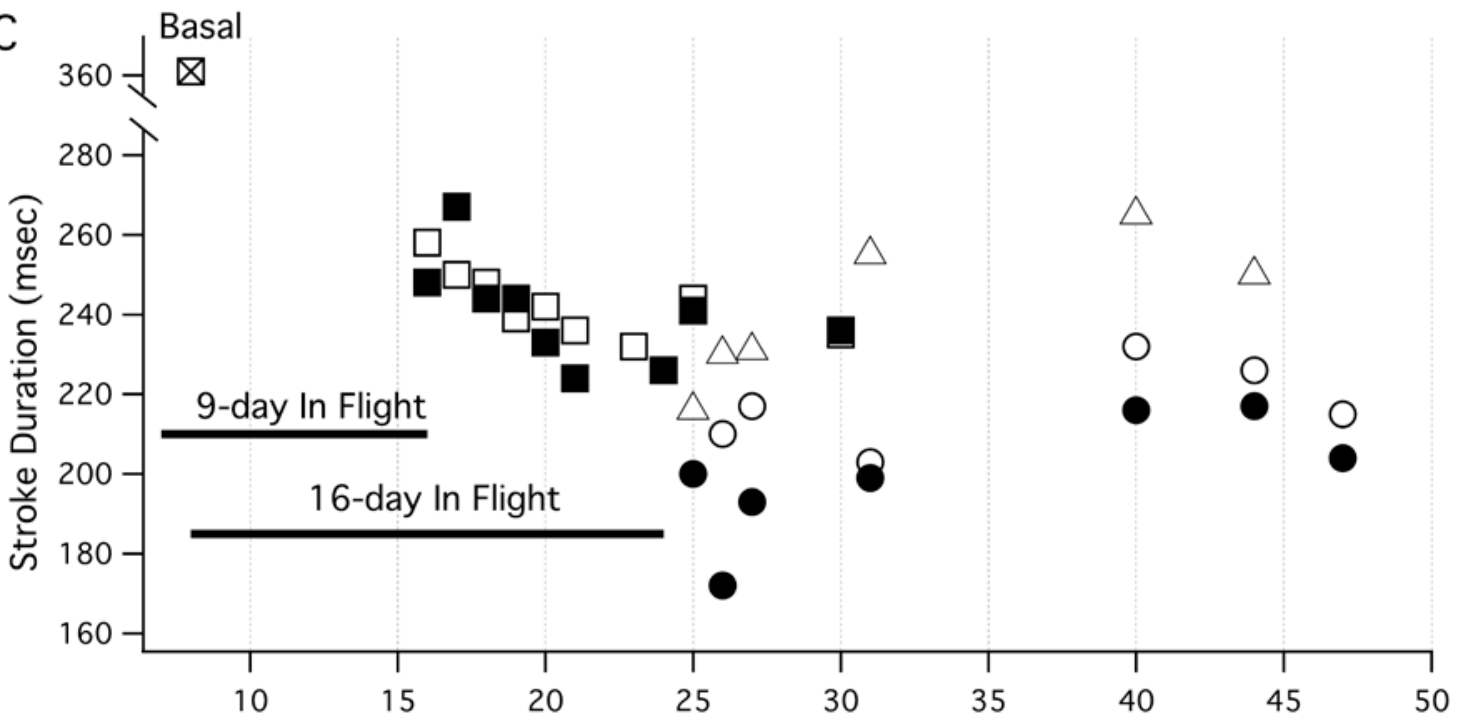

Age (day)

Figure 6. Mean stroke duration for each animal. (A) 9-day mission: There was no difference in swimming speed between flight and control animals after landing except on day 5 (p<0.05) (AGC, R0, R2-R5, n=8; R1, n=9; R7, n=6; R8, 14 n=7; R9, n=4: FLT, R0, n=5; R1, 5, n=9; R2, R3, R8, R14, n=7; R4, 9, n=8; R7, n=6) (B) 16-day mission: Flight animals swam faster than control animals after landing. This difference reached significance on days 2, 3, 7, and 16 (see text). There was no significant change in the swimming speed in flight animals over this time. On R23, the control animals swam faster than on R20 (AGC, R1, R2, R7, R20, R23, n=9; R3, 16, n=7: FLT, R1, 16, n=5; R2-R7, n=6; R20, 23, n=4: VIV, R1-R3, n=7; R7, R20, n=5; R16, n=8; $R 23, n=12$ ) (C) Data from animals in both missions are displayed together with data from the basal animals. 


\section{9-day Mission}

A
Body Weight on Day of Landing (P16)

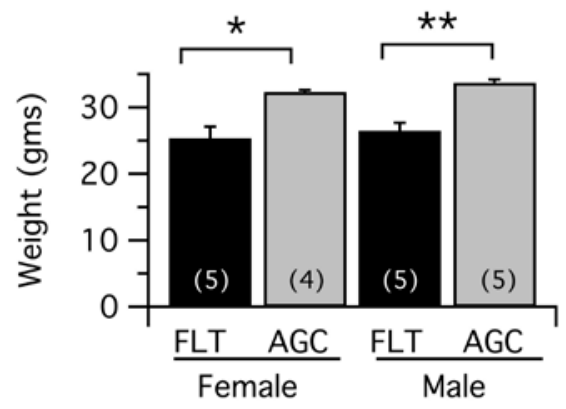

C

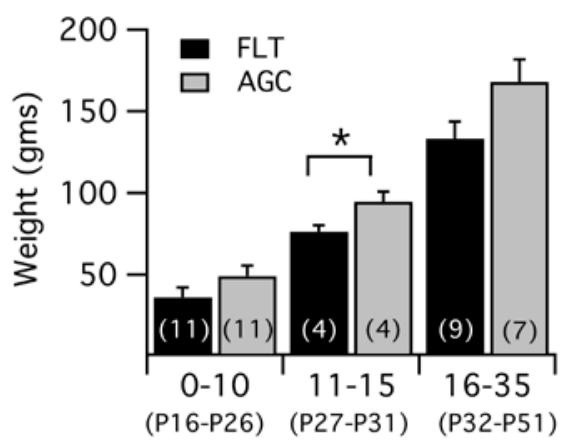

Days after Landing
B

\section{Rate of Weight Gain}

Days 0-30

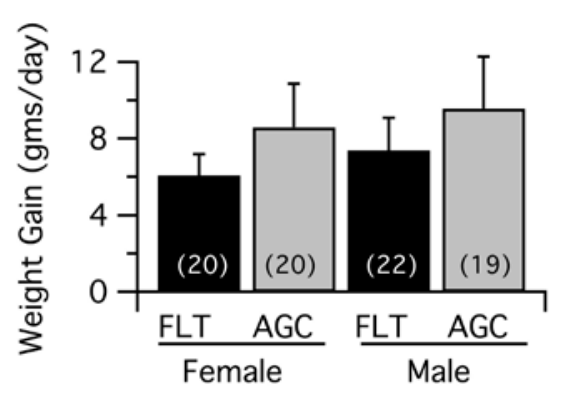

D Males

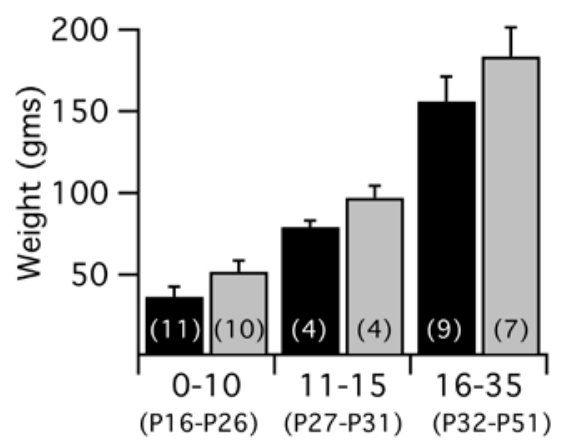

Days after Landing

Figure 7. Weight and rate of weight gain of animals after the 9-day mission. (A) Average weight of each group of animals on the day of landing. (A) Both females and males were included in this mission and are plotted separately. On the day of landing, flight animals of both sexes weighed significantly less than controls. (B) Over the first month after landing, there was no significant difference in the rate of weight gain between flight and control animals (C \& D). Weight of female (C) and male (D) animals over three periods post-flight. The only significant difference between the two groups of animals was for female animals from 11 to 15 days. Data are the mean \pm SEM. $* \mathbf{p}<0.05, * * \mathbf{p}<0.01, * * * \mathbf{p}<0.001, t$-test.

Table 3. Mean maximum (most extended) and minimum (most flexed) ankle and knee joint angles during swimming on R0 and $R 7$ for 9-day flight and control animals.

\begin{tabular}{llccccc}
\hline & & \multicolumn{2}{c}{ Ankle angle (deg) } & & \multicolumn{2}{c}{ Knee angle (deg) } \\
& & Maximum & Minimum & & Maximum & Minimum \\
\cline { 3 - 4 } \cline { 6 - 7 } Day & Group & (most extended) & (most flexed) & & (most extended) & (most flexed) \\
\hline R0 & Flight & $151 \pm 8.8(3)$ & $40 \pm 3.8(3)$ & & $118 \pm 7.1(3)$ & $43 \pm 6.7(3)$ \\
& Control & $138 \pm 1.6(5)$ & $50 \pm 4.5(5)$ & & $121 \pm 6.5(5)$ & $49 \pm 2.1(5)$ \\
R1 & Flight & $153 \pm 5.7(3)$ & $62 \pm 13.1(3)$ & & $96 \pm 0.5(3)$ & $34 \pm 3.7(3)$ \\
& Control & $139 \pm 1.8(3)$ & $65 \pm 5.5(3)$ & & $106 \pm 6.3(3)$ & $47 \pm 3.2(3)$ \\
R7 & Flight & $134 \pm 2.1^{* *}(5)$ & $53 \pm 3.4(5)$ & & $121 \pm 3.6(5)$ & $68 \pm 7.5(5)$ \\
& Control & $123 \pm 1.4(4)$ & $54 \pm 5.4(4)$ & & $122 \pm 1.8(4)$ & $77 \pm 5.5(4)$ \\
R14 & Flight & $133 \pm 3.7(6)$ & $52 \pm 1.1(6)$ & & $116 \pm 2.1(6)$ & $63 \pm 8.8(6)$ \\
& Control & $124 \pm 4.4(4)$ & $57 \pm 3.3(4)$ & & $123 \pm 4.4(4)$ & $73 \pm 6.9(4)$ \\
\hline
\end{tabular}

Values of $\mathrm{n}$ given in parentheses. ${ }^{* *} \mathrm{p}<0.01$, independent samples $t$-test. 

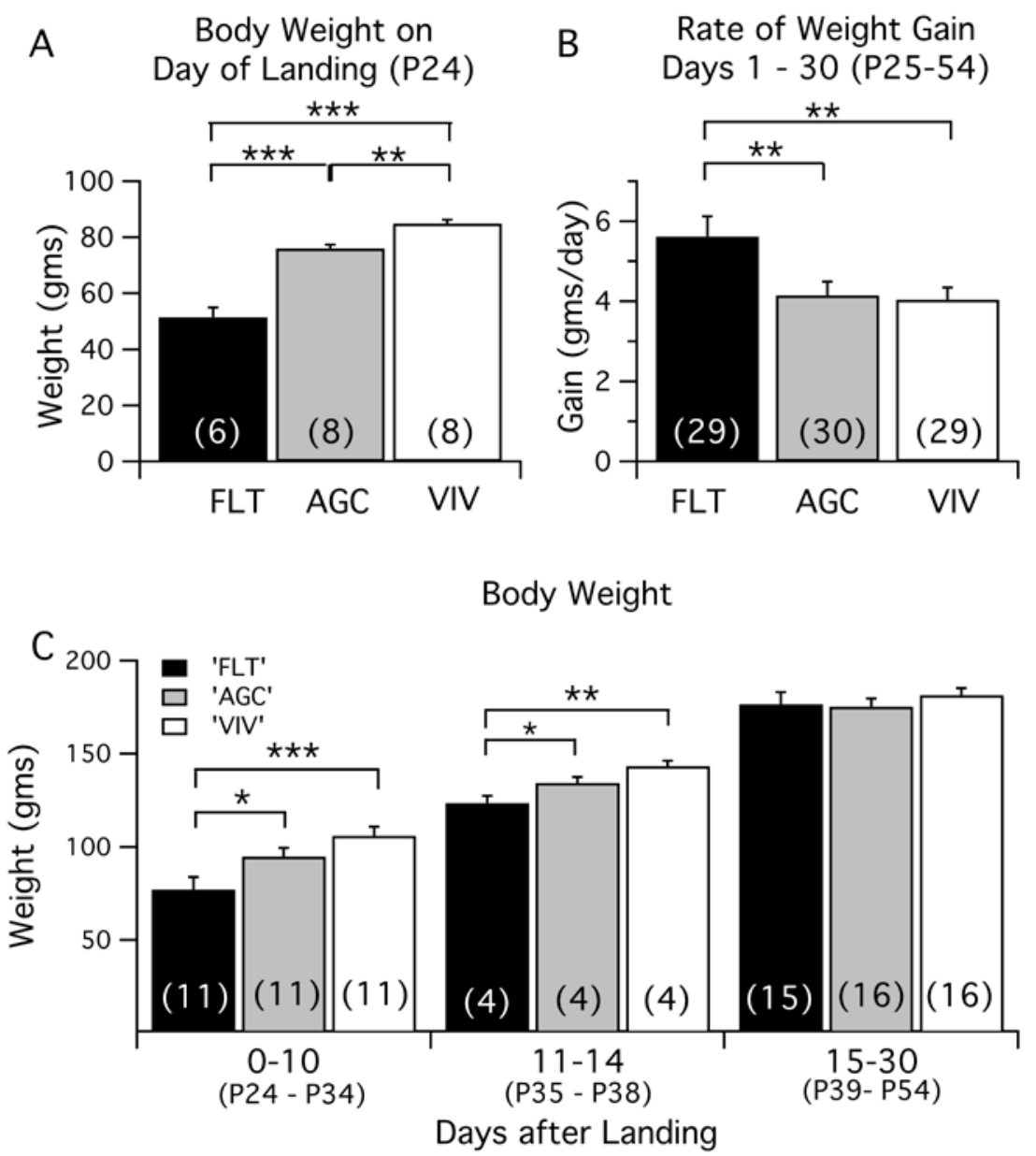

Figure 8. Weight and rate of weight gain of animals after the 16-day mission. (A) Average body weight of each group of animals on the day of landing. (All were females.) All groups were significantly different from each other on the day of landing, with flight animals weighing the least and the vivarium control animals weighing the most. (B) Rate of weight gain for each group between R0 and R30. The rate of weight gain was greater for the flight animals than either control group. (C) Grand mean of mean body weight each day for animal groups during R0-R10, R11-R14, and R15-R30. The flight group remained significantly lighter than the control animals over the first two periods. By R15-R30, all three groups had similar weights. $* \mathbf{p}<0.05, * *$ $\mathbf{p}<0.01, * * * \mathbf{p}<0.001$, one-way ANOVA.

in the AGC cages were lighter than controls in VIV cages $(p=0.004)$.

There was a significant difference among the groups in weight gain over the first month after landing $(\mathrm{F}(2,85)=5.032, \mathrm{p}=.009)$. Post-hoc analysis revealed a larger gain by flight animals compared to vivarium $(\mathrm{p}=0.006)$ and $\mathrm{AGC}$ $(p=0.009)$ controls (Figure 8B). Nevertheless, there was a continued weight difference between flight and control animals and between the two control groups over the first two weeks after landing (Figure 8C).

\section{DISCUSSION}

\section{Comments on Studies of Mammalian Development during Spaceflight}

The limitations inherent to any spaceflight study may be overcome by using young mammals that are weaned as previously described (Walton 
et al., 2005a). On the contrary, serious problems are faced when the animals are not weaned (Maese and Ostrach, 2002). In this study, the problems were mostly a result of cage design, which did not provide enough gripping surface. The most important consequence of this was an inability of the dams to adequately nurse the pups. Inadequate nursing led to high mortality among the pups, particularly for those in the Research Animal Holding Facility (RAHF) cages used for the Neurolab mission, where the mortality rate was $50 \%$ compared to only $10 \%$ for the R3 mission, where bisected Animal Enclosure Modules (AEM) were used (Maese and Ostrach, 2002). Other consequences of inadequate housing and poor maternal-offspring interaction were poor thermoregulation, reduced olfactory and tactile stimulation, and inadequate anogenital stimulation of the pups. The younger animals from the Neurolab mission were available for study only because the crew were able to keep some pups alive by directly hand-feeding, hydrating, and administering antibiotics (Maese and Ostrach, 2002). These findings highlight the importance of in-flight experimental studies and careful hardware design.

This study reports data from young animals that spent either 9 or 16 days in microgravity after developing in a $1 \mathrm{~g}$ environment during the first week of life. To understand the effect of microgravity on motor development, these results must be compared to those of older animals on the same NASA missions, which had developed for twice as long in a $1 \mathrm{~g}$ environment before entering microgravity (Walton et al., 2005b; Walton et al., 2005c).

Overall, these findings show that postnatal motor system development was appropriate to the animal's environment, in spite of the difficult conditions encountered by the animals on the 16day flight. Indeed, in the microgravity environment, there was no stimulus for the surface-righting reflex and the data suggest that the normal development of this reflex stopped. This was reported previously in older animals that spent either 9 or 16 days in microgravity (Walton et al., 2005c). Here, the animals entered microgravity at P7 or P8. Therefore, in all four cases, when they returned to the $1 \mathrm{~g}$ environment, the flight animals used immature tactics more often than age-matched ground controls. The effect of microgravity on vestibular development reflexes was also seen in swimming as the flight animals in all four groups tried to float when they were immersed in water. After the 16-day mission, swimming studies also showed that flight animals had a steeper body angle than the control animals. Some effects were transient, but others lasted for as long as the animals were studied, providing insight into sensitive and critical periods of development.

\section{The Effect of Microgravity on Movement Tactics}

Surface righting

Evaluation of surface righting reflexes in young animals after spaceflight provides a window into the importance of vestibular input in motor development. On the first day of testing for both missions and for both age groups, animals that developed in the microgravity environment used axial righting significantly less often than those who were in a $1 \mathrm{~g}$ environment during same period (Walton et al., 2005c). The time spent in the microgravity environment also had a direct relationship to the degree of impairment in surface righting. The flight animals did not reach control levels of axial righting over the week of testing after the 9-day mission. Although the difference in the use of axial righting between the two groups of animals did not reach statistical significance on R7, this may be due to the increased error in the control animals on that day. However, the use of axial righting did increase after landing and testing for a longer period after landing is needed to find if the flight animals will reach control levels.

Immature tactics persisted for the 23-day test period after the 16-day mission and an increase in the use of axial righting was not seen. Thus, the length of the mission was a factor in this measure. Younger animals also seemed to be more sensitive to the effects of microgravity than older ones. After the 9-day mission, the older flight animals were similar to controls by the second day after landing (Walton et al., 2005c), yet the younger flight group showed significantly reduced axial righting until 7 days after landing (Figure 3A).

The length of the mission also affected other tactics. After the 9-day mission, young flight animals preferred corkscrew righting, whereas 


\section{Harding et al. -- Development of Motor Skills in Microgravity}

after the 16-day mission, they favored ventroflexion. This pattern was also seen in the older groups of animals (Walton et al., 2005c). Surface righting tactics typically develop from ventroflexion to corkscrew to axial righting (Pellis et al., 1991). The increased incidence of ventroflexion after the longer spaceflight suggests that the duration in space is a determinant factor in the development of postnatal behavior.

After the 16-day mission, we saw an increase in the use of axial righting and a reduction in ventroflexion in trials with young flight animals where the head was rotated toward the surface before being released. This is consistent with findings reported in older flight animals (Walton et al., 2005c). In contrast, the use of axial surface righting in control animals was not significantly changed by head rotation, but reductions were seen in the use of $U$ posture, as in the flight group. This indicates that the head rotation may be a necessary first step in mature surface righting, and when the vestibular stimulus that initiates head rotation is reduced or absent, position receptors at the neck may play a larger role in triggering this reflex. Furthermore, it suggests that the elements of this reflex that include the torso and limbs remain intact after development in LEO.

\section{Swimming}

Swimming evaluates both balance and movement. The ability to maintain balance was best seen during the first few seconds that animals were placed in the water. In initial swimming trials, we observed that the flight animals had difficulty maintaining their balance. This was reflected in (1) their tendency to not float before swimming or trying to leave the water by climbing up the side of the tank, (2) their greater body angle (which made it difficult for them to stay afloat), and (3) their tendency to begin swimming sooner than the controls. These impairments were more pronounced in the older animals. The time before swimming was significantly shorter in flight animals only on the first test day in the younger animals. In contrast, flight animals had significantly shorter time before swimming from the first to the last test day (R30) in the older animals (Walton et al., 2005b). Likewise, differences in the behavior before swimming when placed in the water persisted only in the older animals.
These findings are related to the altered vestibular input in the microgravity environment. While changes in the peripheral vestibular system cannot be ruled out, these structures typically mature in the first postnatal week, as indicated by hypergravity studies (Gaboyard et al., 2003). The development of vestibular efferents during the 16day mission does not appear to be sensitive to microgravity (Dememes et al., 2001). In contrast, vestibulospinal pathways remain incomplete at this time (Clarac et al., 2004; Clarac et al., 1998) and intrinsic membrane properties (Straka et al., 2005), spontaneous firing rate, and evoked response of central vestibular neurons are not mature until the end of the first postnatal month in rodents (Johnston and Dutia, 1996; Lannou et al., 1979). Thus, upon landing, the animals in this study were still within the critical period for central vestibular system development.

In addition to vestibular system development, the timeframe from P7 to P16 overlaps with maturation of behaviors including locomotion (Altman and Sudarshan, 1975; Westerga and Gramsbergen, 1990) and swimming (Gruner and Altman, 1980). Likewise, at the cellular level, P7 to P16 is a time when spinal motor neurons (Navarrete and Vrbová, 1983; Walton and Navarrete, 1991) and their descending inputs (Rajaofetra et al., 1992; Tanaka et al., 1992) continue to mature, and when $N$-methyl-Daspartate (NMDA) receptors (Kalb et al., 1992) are transiently expressed, polyneuronal innervation is eliminated, and skeletal muscle fibers differentiate (Balice-Gordon and Lichtman, 1993; Brown et al., 1976; Navarrette and Vrbova, 1993; Redfern, 1970). An anatomical study of lumbar motor neurons in the older animals from the 16-day mission found that dendritic trees of medial motor neurons, which innervate axial musculature, were reduced (Inglis et al., 2000). Thus, several components of the central vestibular and motor systems are sensitive to environmental factors in microgravity.

\section{The Effect of Microgravity on Movement Speed}

\section{Surface righting}

There were no differences in surface righting speed between flight and control animals, which is consistent with the findings in older animals on 
the same missions (Walton et al., 2005c). Although surface righting speed is transiently impaired when gravitational forces are disturbed during development, especially with reference to righting the head (Walton, 1998; Walton et al., 1997), in these initial studies we did not take into account the tactics used, which were largely immature in flight animals. Generally, immature tactics involving ventroflexion take more time than mature axial righting. When speed was evaluated as a function of tactics used, no differences between groups were observed.

\section{Swimming}

The effects of microgravity on swimming speed, as estimated by stroke duration, seemed to be more sensitive to the length of time in spaceflight rather than their age in LEO. Swimming was faster than at launch at landing in both flight and control animals. This is consistent with an increase in swimming speed during development over the first two weeks of life in a 1 $g$ environment (Beckoff and Trainer, 1979; (Clarac et al., 1998). After the 9-day mission, swimming speed was similar in flight and control animals over the first two weeks after landing. In contrast, flight animals swam faster than the controls after the 16-day mission. This persisted for two weeks after landing in the younger animals and until the last test day (R30) in the older animals (Walton et al., 2005b). However, this difference between the younger and older animals may be a function of the small numbers of young flight animals available for testing and resultant large standard error of the mean. This study highlights the need for additional spaceflight studies on developing animals to clarify the long-term effects on vestibular reflexes as a function of age.

These findings suggest that myelination, and other elements that determine movement speed, proceed normally or are perhaps enhanced in the absence of gravity. However, studies investigating the effects of gravity on myelination have produced conflicting results. One study found that simulated microgravity stimulated oligodendrocyte production of myelin in human embryonic brain-derived neural stem cells (Espinosa-Jeffrey et al., 2016). In contrast, C57BL/6 adult mice subjected to hindlimb unloading showed prominent myelin destruction in spinal glial cells (Chelyshev et al., 2014). Because the hindlimb unloading model of microgravity places different stressors on the spinal cord than microgravity itself, this finding may not be directly applicable to spaceflight research.

\section{Effects of Nutrition and Stress}

The animals in this study depended on nursing for their nourishment. This proved to be challenging in the microgravity environment due to housing. This was seen in the difference in body weight between flight and control animals on the day of landing after both the 9-day and 16day mission.

Although it is likely that the flight animals were malnourished, the question of interest is the contribution of this factor to the differences in motor behavior seen between flight and control animals. Indeed, malnutrition can have a significant effect on postnatal motor function (Horiquini Barbosa et al., 2016). Nevertheless, the differences in the behavioral measures used in this study are consistent with having spent time in LEO, rather than with the flight animals being malnourished. The most direct argument in support of this view is that the differences seen in the young flight animals are similar to those seen in the older flight animals that had the same weight as controls at landing (Walton et al., 2005b; Walton et al., 2005c). Undernutrition is not necessarily associated with changes in cortical development (Fernandez et al., 1993), and although it can reduce basal dendritic length and branching, environmental stimulation can compensate for this impairment (Pascual et al., 1996).

Another possible confounding factor is that the younger animals experienced more stress than the older ones due to differences in cages, noise, lighting conditions, and experience in microgravity. In a related study, neonatal rats subjected to maternal separation stress from P2 to P21 showed some delay in the acquisition of air righting, surface righting, and postural righting reflexes (Mesquita et al., 2007). However, these observed effects were transient, and surface righting was restored by P3 in males and by P5 in females, even when the stress continued. In contrast, our results suggest that lack of gravitational input during a critical period of 
development beginning on P7 or P8 can produce long-term effects on righting tactics. Therefore, we contend that the effects seen cannot simply be due to stress.

Space-based biological studies have limitations that affect interpretation of the findings. The most important of these in conducting behavioral studies is perhaps the limitation of the number of animals that may be studied. Limitations in data collection are due to both the constrained space available on the space shuttle and the post-flight availability of the animals. Nevertheless, these findings provide a first look at the relative importance of age and mission length on some aspects of postnatal motor development.

Although these findings must be considered preliminary, they are consistent with the idea that postnatal nervous and muscular system development are adaptations to the environment, and that spaceflight offers a unique environment for further study.

\section{ACKNOWLEDGEMENTS}

Special thanks are due to Dr. Frank Sulzman and Dr. Wally Wolfe, who along with Rodolfo Llinás conceived of Neurolab; and to Dr. Joan Vernikos for her vision of what space research could be. We are grateful to the Neurolab mission crew, particularly Dr. Rick Linnehan, our able inflight veterinarian, as well as Dr. Jay Buckey and Dr. Dave Williams, our "space scientists." We would also like to thank Dr. Louis Ostrach, who was there from the start; Dr. Chris Maese, who kept it all together; and Mrs. Carol Elland, an essential guide through the mysteries of spaceflight research. Finally, we would like to thank the reviewers who helped make this a more useful report for future space studies. This study was supported by NINDS, NICHD NS/HD33467, NASA, NAF2-662, NAG2-951, and the Department of the Navy NAG2-978 (to KW \& Rodolfo Llinás).

\section{REFERENCES}

Abe C, Tanaka K, Awazu C, Morita H (2008) Impairment of vestibular-mediated cardiovascular response and motor coordination in rats born and reared under hypergravity. American Journal of
Physiology - Regulatory, Integrative and Comparative Physiology 295: R173-R180

Altman J, Sudarshan K (1975) Postnatal development of locomotion in the laboratory rat. Animal Behavior 23: 896-920

Bagic AI, Barkley GL, Rose DF, Ebersole JS, Committee ACPG (2011) American Clinical Magnetoencephalography Society Clinical Practice Guideline 4: qualifications of MEGEEG personnel. Journal of Clinical Neurophysiology 28: 364-365

Baldi A, Calia E, Ciampini A, Riccio M, Vetuschi A, Persico AM, Keller F (2000) Deafferentation-induced apoptosis of neurons in thalamic somatosensory nuclei of the newborn rat: critical period and rescue from cell death by peripherally applied neurotrophins. European Journal of Neuroscience 12: 2281-2290

Balice-Gordon RJ, Lichtman JW (1993) In vivo observations of pre- and postsynaptic changes during the transition from multiple to single innervation at developing neuromuscular junctions. Journal of Neuroscience 13: 834-855

Bekoff A, Trainer W (1979). The development of interlimb co-ordination during swimming in postnatal rats. Journal of Experimental Biology 83: 1-11

Berenbaum SA, Beltz AM (2011) Sexual differentiation of human behavior: effects of prenatal and pubertal organizational hormones. Frontiers in Neuroendocrinology 32: $183-200$

Bouet V, Gahery Y, Lacour M (2003) Behavioural changes induced by early and long-term gravito-inertial force modification in the rat. Behavioural Brain Research 139: 97-104

Bouet V, Wubbels RJ, de Jong HA, Gramsbergen A (2004) Behavioural consequences of hypergravity in developing rats. Developmental Brain Research 153: 69-78

Brocard F, Clarac F, Vinay L (2003) Gravity influences the development of inputs from the brain to lumbar motoneurons in the rat. NeuroReport 14: 1697-1700

Brown MC, Jansen JK, Van Essen D (1976) Polyneuronal innervation of skeletal muscle in new-born rats and its elimination during maturation. Journal of Physiology 261: 387- 
Chelyshev YA, Muhamedshina YO, Povysheva TV, Shaymardanova GF, Rizvanov AA, Nigmetzyanova MV, Tiapkina OV, Bondarenko NI, Nikolskiy EE, Islamov RR (2014) Characterization of spinal cord glial cells in a model of hindlimb unloading in mice. Neuroscience 280: 328-339

Clarac F, Pearlstein E, Pflieger JF, Vinay L (2004) The in vitro neonatal rat spinal cord preparation: a new insight into mammalian locomotor mechanisms. Journal of Comparative Physiology A 190: 343-357

Clarac F, Vinay L, Cazalets JR, Fady JC, Jamon M (1998) Role of gravity in the development of posture and locomotion in the neonatal rat. Brain Research Reviews 28: 35-43

Coleman J, Blatchley BJ, Williams JE (1982) Development of the dorsal and ventral cochlear nuclei in rat and effects of acoustic deprivation. Brain Research 256: 119-123

DeFelipe J, Arellano JI, Merchan-Perez A, Gonzalez-Albo MC, Walton $\mathrm{K}$, Llinas $\mathrm{R}$ (2002) Spaceflight induces changes in the synaptic circuitry of the postnatal developing neocortex. Cerebral Cortex 12: 883-891

Dememes D, Dechesne CJ, Venteo S, Gaven F, Raymond J (2001) Development of the rat efferent vestibular system on the ground and in microgravity. Developmental Brain Research 128: 35-44

Espinosa-Jeffrey A, Nguyen K, Kumar S, Toshimasa O, Hirose R, Reue K, Vergnes L, Kinchen J, Vellis J (2016) Simulated microgravity enhances oligodendrocyte mitochondrial function and lipid metabolism. Journal of Neuroscience Research 94: 14341450

Fernandez V, Pascual R, Ruiz S (1993) Early life environmental deterioration, nutrition and ontogenesis of the motor cortex in the rat: a Golgi study. Biology of the Neonate 64: 245253

Frazier LL, Brunjes PC (1988) Unilateral odor deprivation: early postnatal changes in olfactory bulb cell density and number. Journal of Comparative Neurology 269: 355370

Gaboyard S, Sans A, Lehouelleur J (2003)

Differential impact of hypergravity on maturating innervation in vestibular epithelia during rat development. Developmental Brain Research 143: 15-23

Gabriel M, Frippiat JP, Frey H, Horn ER (2012) The sensitivity of an immature vestibular system to altered gravity. Journal of Experimental Zoology Part A 317: 333-346

Gruner JA, Altman J (1980) Swimming in the rat: Analysis of locomotor performance in comparison to stepping. Experimental Brain Research 40: 374-382

Hains BC, Klein JP, Saab CY, Craner MJ, Black JA, Waxman SG (2003) Upregulation of sodium channel Nav1.3 and functional involvement in neuronal hyperexcitability associated with central neuropathic pain after spinal cord injury. Journal of Neuroscience 23: $8881-8892$

Harris JA, Rubel EW (2006) Afferent regulation of neuron number in the cochlear nucleus: cellular and molecular analyses of a critical period. Hearing Research 216-217: 127-137

Horiquini Barbosa E, Vallim JH, Lachat JJ, de Castro VL (2016) Assessments of motor abnormalities on the grid-walking and footfault tests from undernutrition in Wistar rats. Journal of Motor Behavior 48: 5-12

Hubel DH, Wiesel TN (1970) The period of susceptibility to the physiological effects of unilateral eye closure in kittens. Journal of Physiology 206: 419-436

Inglis FM, Zuckerman KE, Kalb RG (2000) Experience-dependent development of spinal motor neurons. Neuron 26: 299-305

Johnston AR, Dutia MB (1996) Postnatal development of spontaneous tonic activity in mouse medial vestibular nucleus neurones. Neuroscience Letters 219: 17-20

Kalb RG, Lidow MS, Halsted MJ, Hockfield S (1992) N-methyl-D-aspartate receptors are transiently expressed in the developing spinal cord ventral horn. Proceedings of the National Academy of Science of the United States of America 89: 8502-8506

Knudsen EI (2004) Sensitive periods in the development of the brain and behavior. Journal of Cognitive Neuroscience 16: 14121425

Lannou J, Precht W, Cazin L (1979) The postnatal development of functional properties of 


\section{Harding et al. -- Development of Motor Skills in Microgravity}

central vestibular neurons in the rat. Brain Research 175: 219-232

Maese C, Ostrach L (2002) Neurolab: Final Report for the Ames Research Center Payload, Moffett Field: NASA

Meisami E (1978) Influence of early anosmia on the developing olfactory bulb. Progress in Brain Research 48: 211-229

Mesquita AR, Pego JM, Summavielle T, Maciel P, Almeida OF, Sousa N (2007) Neurodevelopment milestone abnormalities in rats exposed to stress in early life. Neuroscience 147: 1022-1033

Morey-Holton E, Globus RK, Kaplansky A, Durnova G (2005) The hindlimb unloading rat model: literature overview, technique update and comparison with space flight data. Advances in Space Biology Medicine 10: $7-40$

Navarrette R, Vrbová G (1993) Activitydependent interactions between motoneurones and muscles: their role in the development of the motor unit. Progress in Neurobiology 41: 93-124

Navarrete R, Vrbová G (1983) Changes of activity patterns in slow and fast muscles during postnatal development. Developmental Brain Research 8: 11-19

Pascual R, Hervias MC, Figueroa HR (1996) Effects of preweaning environmental stimulation on neuronal and behavioral impairment produced by undernutrition. Biology of the Neonate 70: 165-172

Pellis VC, Pellis SM, Teitelbaum P (1991) A descriptive analysis of the postnatal development of contact-righting in rats (Rattus norvegicus). Developmental Psychobiology 24: 237-263

Rajaofetra N, Poulat P, Marlier L, Geffard M, Privat A (1992) Pre- and postnatal development of noradrenergic projections to the rat spinal cord: an immunocytochemical study. Developmental Brain Research 67: 237-246

Raymond J, Dememes D, Blanc E, Sans N, Venteo S, Dechesne CJ (2000) Developmental study of rat vestibular neuronal circuits during a spaceflight of 17 days. Journal of Gravitational Physiology 7: P55-P58
Redfern PA (1970) Neuromuscular transmission in newborn rats. Journal of Physiology 209: 701-709

Ronca AE, Alberts JR (2000) Effects of prenatal spaceflight on vestibular responses in neonatal rats. Journal of Applied Physiology 89: $2318-2324$

Ronca AE, Fritzsch B, Bruce LL, Alberts JR (2008) Orbital spaceflight during pregnancy shapes function of mammalian vestibular system. Behavioral Neuroscience 122: 224232

Straka H, Vibert N, Vidal PP, Moore LE, Dutia MB (2005) Intrinsic membrane properties of vertebrate vestibular neurons: function, development and plasticity. Progress in Neurobiology 76: 349-392

Tanaka H, Mori S, Kimura H (1992) Developmental changes in the serotoninergic innervation of hindlimb extensor motoneurons in neonatal rats. Developmental Brain Research 65: 1-12

Van der Loos H, Woolsey TA (1973) Somatosensory cortex: structural alterations following early injury to sense organs. Science 179: 395-398

Walton K (1998) Postnatal development under conditions of simulated weightlessness and space flight. Brain Research Reviews 28: 2534

Walton K, Harding S, Anschel D, Harris Y, Llinas $R$ (2005a) The effects of microgravity on the development of surface righting in rats. Journal of Physiology 565: 593-608

Walton K, Heffernan C, Sulica D, Benavides L (1997) Changes in gravity influence rat postnatal motor system development: from simulation to space flight. Gravitational Space Biology Bulletin 10: 111-118

Walton KD, Benavides L, Singh N, Hatoum N (2005b) Long-term effects of microgravity on the swimming behavior of young rats. Journal of Physiology 565: 609-626

Walton KD, Harding S, Anschel D, Harris YT, Llinas R (2005c) The effects of microgravity on the development of surface righting in rats. Journal of Physiology 565: 593-608

Walton KD, Lieberman D, Llinas A, Begin M, Llinas RR (1992) Identification of a critical period for motor development in neonatal rats. Neuroscience 51: 763-767 


\section{Harding et al. -- Development of Motor Skills in Microgravity}

Walton KD, Navarrete R (1991) Postnatal changes in motoneurone electrotonic coupling studied in the in vitro rat lumbar spinal cord. Journal of Physiology 433: 283305

Westerga J, Gramsbergen A (1990) The development of locomotion in the rat. Developmental Brain Research 57: 163-174

Wiesel T, Hubel D (1963a) Single-cell responses in striate cortex of kittens deprived of vision in one eye. Journal of Neurophysiology 26: 1003-1017
Wiesel TN (1982) Postnatal development of the visual cortex and the influence of the environment. Nature 299: 583-591

Wiesel TN, Hubel DH (1963b) Effects of visual deprivation on morphology and physiology of cells in the cat's lateral geniculate cortex. Journal of Neurophysiology 26: 978-993

Wubbels R, Bouet V, de Jong H, Gramsbergen A (2004) Development of sensory motor reflexes in $2 \mathrm{G}$ exposed rats. Journal of Gravitational Physiology 11: P21-P22 
Harding et al. -- Development of Motor Skills in Microgravity

\section{SUPPLEMENTARY TABLES}

Supplementary Table 1. Significant differences in the righting tactics between 9-day mission flight and control animals (two-way t-test). ${ }^{1}$

\begin{tabular}{|c|c|c|c|c|c|}
\hline \multirow[b]{2}{*}{ Day } & \multicolumn{5}{|c|}{ Righting tactic } \\
\hline & Axial & Corkscrew & UC & $\mathbf{L}$ & Ventroflexion \\
\hline Ro & $\begin{array}{c}t(17)=5.731 \\
p=0.0001\end{array}$ & & $\begin{array}{c}t(9)=-3.199 \\
p=0.011\end{array}$ & $\begin{array}{c}t(9)=-2.358 \\
p=0.043\end{array}$ & $\begin{array}{c}t(9)=-3.35 \\
p=0.005\end{array}$ \\
\hline R1 & $\begin{array}{c}t(16)=4.289 \\
p=0.001\end{array}$ & $\begin{array}{c}t(16)=-3.026 \\
p=0.008\end{array}$ & $\begin{array}{c}t(8)=-2.986 \\
p=0.01\end{array}$ & & \\
\hline $\mathrm{R} 2$ & $\begin{array}{c}t(16)=5.394 \\
p=0.0001\end{array}$ & $\begin{array}{c}t(16)=-2.724 \\
p=0.015\end{array}$ & & & $\begin{array}{c}t(16)=-2.6 \\
p=0.019\end{array}$ \\
\hline R3 & $\begin{array}{c}t(16)=3.734 \\
p=0.002\end{array}$ & $\begin{array}{c}t(16)=-3.438 \\
p=0.003\end{array}$ & & & \\
\hline $\mathrm{R} 4$ & $\begin{array}{c}t(15)=2.745 \\
p=0.015\end{array}$ & & & & $\begin{array}{c}t(15)=-2.155 \\
p=0.048\end{array}$ \\
\hline R5 & $\begin{array}{c}t(9.8)=2.557 \\
p=00.029\end{array}$ & $\begin{array}{c}t(8.5)=-3.089 \\
p=0.014\end{array}$ & & & \\
\hline $\mathrm{R} 6$ & $\begin{array}{c}t(9.2)=2.363 \\
p=0.042\end{array}$ & & & & \\
\hline
\end{tabular}

These data are plotted in Figures 3 and 4. 
Harding et al. -- Development of Motor Skills in Microgravity

Supplementary Table 2. Significant differences in the righting tactics between flight and control animals after the 16-day mission. (one-way ANOVA and post-hoc test). ${ }^{1}$

\begin{tabular}{|c|c|c|c|c|c|c|}
\hline \multirow[b]{2}{*}{ Day } & \multirow[b]{2}{*}{ Axial } & \multicolumn{5}{|c|}{ Righting tactic } \\
\hline & & Corkscrew & $U$ & UC & $\mathbf{L}$ & Ventroflexion \\
\hline R2 & $\begin{array}{c}F(2,15)=3.877 \\
p=0.044\end{array}$ & & $\begin{array}{c}F(2,15)=9.019 \\
p=0.003\end{array}$ & & & $\begin{array}{c}F(2,15)=21.043 \\
p=0.0001\end{array}$ \\
\hline FLT-AGC & & & $p=0.003$ & & & $p=0.0001$ \\
\hline FLT-VIV & $p=0.014$ & & $p=0.001$ & & & $p=0.0001$ \\
\hline R3 & $\begin{array}{c}F(2,16)=12.566 \\
p=0.001\end{array}$ & & $\begin{array}{c}F(2,16)=18.46 \\
p=0.0001\end{array}$ & $\begin{array}{c}F(2,16)=4.948 \\
p=0.021\end{array}$ & & $\begin{array}{c}F(2,16)=15.68 \\
p=0.0001\end{array}$ \\
\hline FLT-AGC & $p=0.0001$ & & $p=0.002$ & $p=0.019$ & & $p=0.0001$ \\
\hline FLT-VIV & $p=0.001$ & & $p=0.0001$ & $p=0.009$ & & $p=0.0001$ \\
\hline R5 & $\begin{array}{c}F(2,16)=27.176 \\
p=0.0001\end{array}$ & & $\begin{array}{c}F(2,16)=5.839 \\
p=0.012\end{array}$ & $\begin{array}{c}F(2,16)=5.723 \\
p=0.013\end{array}$ & & $\begin{array}{c}F(2,16)=23.897 \\
p=0.0001\end{array}$ \\
\hline FLT-AGC & $p=0.0001$ & & $p=0.006$ & $p=0.007$ & $p=0.030$ & $p=0.0001$ \\
\hline FLT-VIV & $p=0.0001$ & & $p=0.012$ & $p=0.010$ & $p=0.043$ & $p=0.0001$ \\
\hline R7 & $\begin{array}{c}F(2,15)=7.660 \\
p=0.005\end{array}$ & & & & & $\begin{array}{c}F(2,15)=9.843 \\
p=0.002\end{array}$ \\
\hline FLT-AGC & $p=0.002$ & & $\mathrm{p}=0.017$ & & $\mathrm{p}=0.033$ & $p=0.001$ \\
\hline FLT-VIV & $p=0.005$ & & & & $p=0.042$ & $p=0.008$ \\
\hline R10 & & & $\begin{array}{c}F(2,10)=5.381 \\
p=0.026\end{array}$ & & & $\begin{array}{c}F(2,10)=8.331 \\
p=0.007\end{array}$ \\
\hline FLT-AGC & & & $p=0.016$ & & & $p=0.005$ \\
\hline FLT-VIV & & & $p=0.024$ & & & $p=0.008$ \\
\hline R23 & $\begin{array}{c}F(2,16)=11.626 \\
p=0.001\end{array}$ & & & $\begin{array}{c}F(2,16)=9.947 \\
p=0.002\end{array}$ & & $\begin{array}{c}F(2,16)=17.750 \\
p=0.0001\end{array}$ \\
\hline FLT-AGC & $p=0.001$ & & & $p=0.001$ & & $p=0.0001$ \\
\hline FLT-VIV & $p=0.0001$ & & $p=0.046$ & $p=0.002$ & $\mathrm{p}=0.046$ & $p=0.0001$ \\
\hline
\end{tabular}

${ }^{1}$ These data are plotted in Figures 3 and 4. 